\title{
Dynamic interaction of the cavitating propeller tip vortex with the rudder
}

\author{
Jan A. Szantyr, \\ Gdansk University of Technology
}

\begin{abstract}

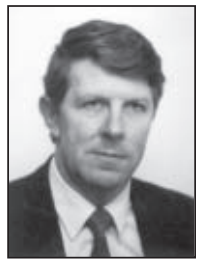

The hydrodynamic interaction between the ship propeller and the rudder has many aspects. One of the most interesting is the interaction between the cavitating tip vortex shed from the propeller blades and the rudder. This interaction leads to strongly dynamic behaviour of the cavitating vortex, which in turn generates unusually high pressure pulses in its vicinity. Possibly accurate prediction of these pulses is one of the most important problems in the hydrodynamic design of a new ship. The paper presents a relatively simple computational model of the propeller cavitating tip vortex behaviour close to the rudder leading edge. The model is based on the traditional Rankine vortex and on the potential solution of the dynamics of the cylindrical sections of the cavitating kernel passing through the strongly variable pressure field in the vicinity of the rudder leading edge. The model reproduces numerically the experimentally observed process of initial compression of the vortex kernel in the high pressure region near the stagnation point at the rudder leading edge and subsequent explosive growth of the kernel in the low pressure region further downstream. Numerical simulation of this process enables computation of the additional pressure pulses generated due to this phenomenon and transmitted onto the hull surface. This new numerical model of the cavitating tip vortex is incorporated in the modified unsteady lifting surface program for prediction of propeller cavitation, which has been successfully used in the process of propeller design for several years and which recently has been extended to include the effects of propeller-rudder interaction. The results of calculations are compared with the experimental measurements and they demonstrate reasonable agreement between theory and physical reality.
\end{abstract}

Keywords : propeller blades, rudder, cavitating, tip vortex shed

\section{STATEMENT OF THE PROBLEM}

The physical mechanisms and consequences of the interaction between ship propeller and rudder have been the focus of considerable research effort in the recent years (see for example $[2,4,5,6])$. The results of this research show first of all that cavitation on the rudder is a fairly frequent phenomenon and that its consequences may be as important for the ship operation as cavitation on the propeller itself. Secondly, it seems that sufficiently accurate prediction of sheet cavitation on the rudder is practically possible using variety of methods, ranging from boundary element method to commercial RANS codes. However, it seems that another aspect of propeller - rudder interaction has not received sufficient attention yet. This aspect is the propeller cavitating tip vortex interaction with the rudder.

Cavitation tunnel experiments with propeller - rudder configurations show that this interaction leads to very dynamic behaviour of the sections of the cavitating kernel in the vicinity of the rudder leading edge. Examples of the selected stages of this process are shown in Figs. 1, 2, 3 and 4. Careful analysis of the photographs shows that the sections of the tip vortex cavitating kernel at first enter the high pressure area in front of the rudder leading edge stagnation point, where they undergo compression. Then they slide downstream along the rudder into the area of low pressure, where they increase their diameter and later disintegrate into a cloud of bubbles. This process may take place even when there is no sheet cavitation on the rudder. It leads to generation of additional strong pressure pulses and it may cause erosion damage on the rudder.

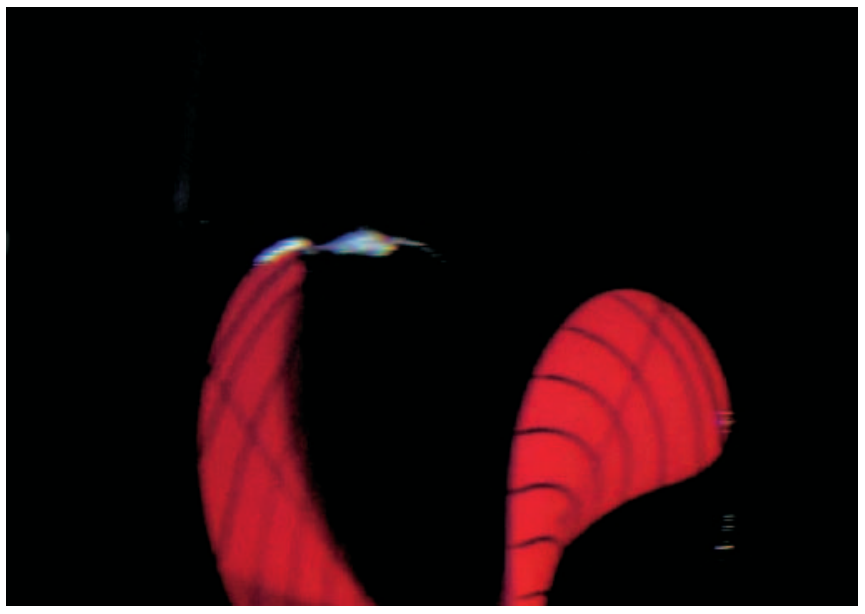

Fig.1. Cavitating tip vortex approaching ruder-phase 1 . 


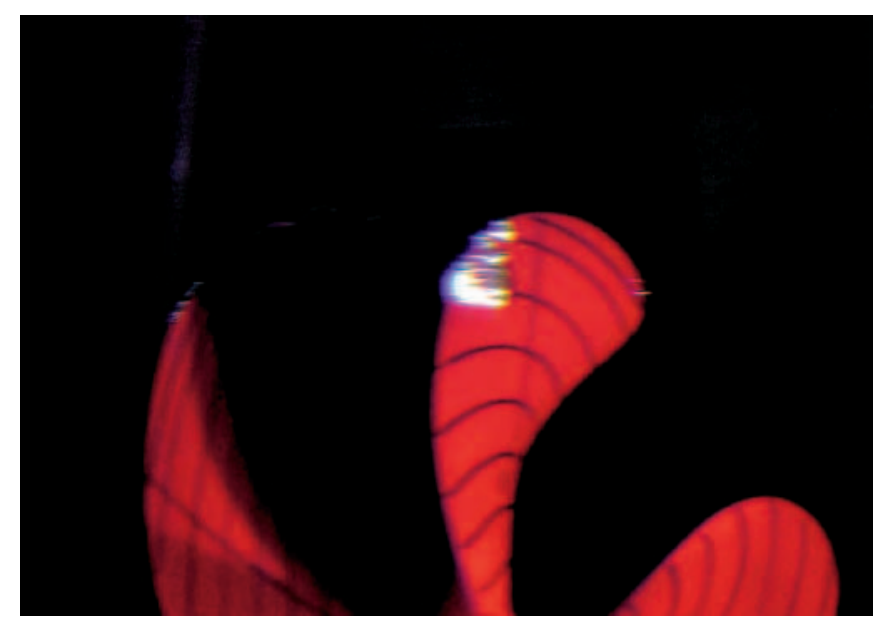

Fig.2. Cavitating tip vortex approaching rudder-phase 2.

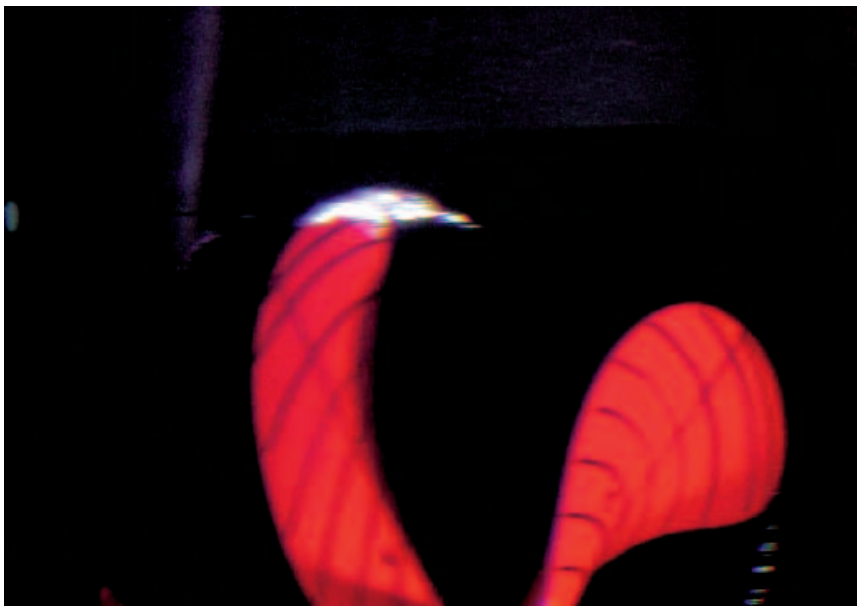

Fig.3. Cavitating tip vortex approaching rudder-phase 3.

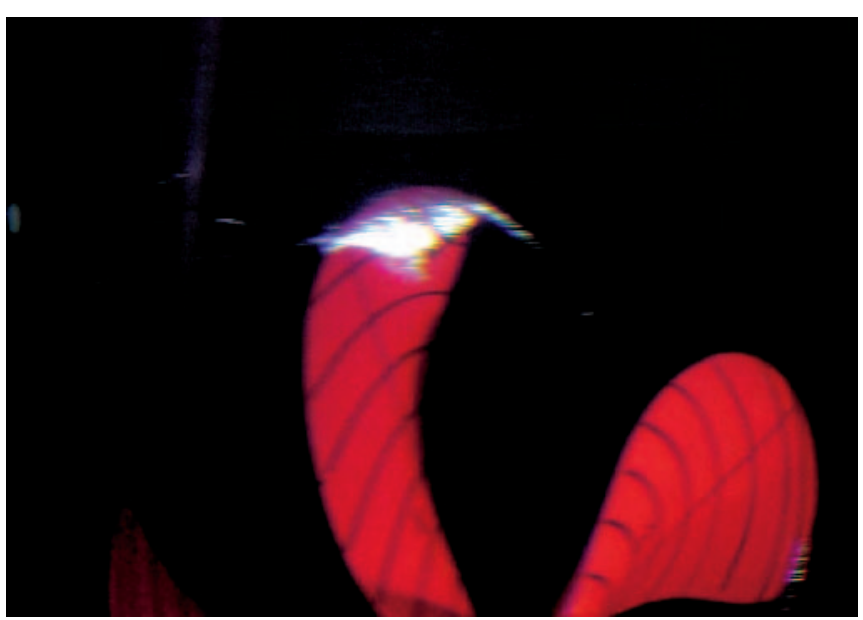

Fig.4. Cavitating tip vortex approaching rudder-phase 4.

Simultaneous measurements of pressure pulses on the ship hull model with and without rudder show a considerable increase of pressure harmonic amplitudes with rudder present - cf. Tab. 1. In this case all three pressure pick-ups are located along the ship symmetry plane, with point no. 1 located in front of the propeller, point no. 2 directly above propeller and point no. 3 at the rudder leading edge. The details of the model propeller rudder configuration are shown in Fig. 8. The Tab.1 includes amplitudes of the first blade frequency harmonic A1 and second harmonic A2, both re-calculated to full scale. As there was no cavitation on the rudder at zero deflection angle and no visible change in cavitation on the propeller blades due to rudder presence, this increase may be attributed to the above described dynamic interaction of the cavitating tip vortex with the rudder. A marked increase in the higher order harmonic amplitudes points to the complicated character of this interaction.

The above presented experimental evidence was the inspiration for development of the model described in [9] and this paper. The primary purpose of this model is to enable calculation of the additional pressure pulses generated by the cavitating tip vortex in interaction with the rudder.

Tab. 1. Results of measurements, $[\mathrm{kPa}]$.

\begin{tabular}{|c|c|c|c|c|}
\hline \multirow{2}{*}{$\begin{array}{c}\text { Pick-up } \\
\text { no. }\end{array}$} & \multicolumn{2}{|c|}{ With rudder } & \multicolumn{2}{c|}{ Without rudder } \\
\cline { 2 - 5 } & $\mathbf{A 1}$ & $\mathbf{A 2}$ & $\mathbf{A 1}$ & $\mathbf{A 2}$ \\
\hline 1 & 0.976 & 0.773 & 0.730 & 0.569 \\
\hline 2 & 2.630 & 2.960 & 1.963 & 2.310 \\
\hline 3 & 2.731 & 3.036 & 1.560 & 2.071 \\
\hline
\end{tabular}

\section{DESCRIPTION \\ OF THE COMPUTATIONAL MODEL}

The model of the propeller tip vortex interaction with the rudder presented in this paper was developed as an extension of the lifting surface method for prediction of unsteady propeller cavitation [7], [8]. This method was modified recently to include the unsteady hydrodynamic interaction between propeller and rudder. The original method produces the time-dependent intensity of the propeller tip vortex as the function of the variable loading of the propeller blade passing through the nonuniform velocity field of the ship wake. Typically the tip vortex is divided into sections corresponding to the angular propeller blade step of $5 \mathrm{deg}$, each section having constant vortex intensity. Geometry of the tip vortex follows the streamline, including the velocity induced by the propeller and by the rudder. The sketch of this model is shown in Fig. 5.

The extended tip vortex model is based on the following assumptions:

$>$ the velocity and pressure fields induced by the vortex is calculated by using the Rankine vortex model

$>$ the diameter of the Rankine vortex kernel is related to the boundary layer thickness in the tip region of the blade

$>$ the cavitating vortex kernel of the tip vortex is divided into small sections, each of which is modelled by a circular cylinder

$>$ dynamics of each section is modeled by a properly adapted Rayleigh-Plesset equation solved numerically in the time/ space by using Runge-Kutta method

$>$ the primary purpose of the model is to describe the first cycle of compression/rebound of the cavitating tip vortex sections, disregarding subsequent disintegration of the vortex kernel into bubble and cloud cavitation.

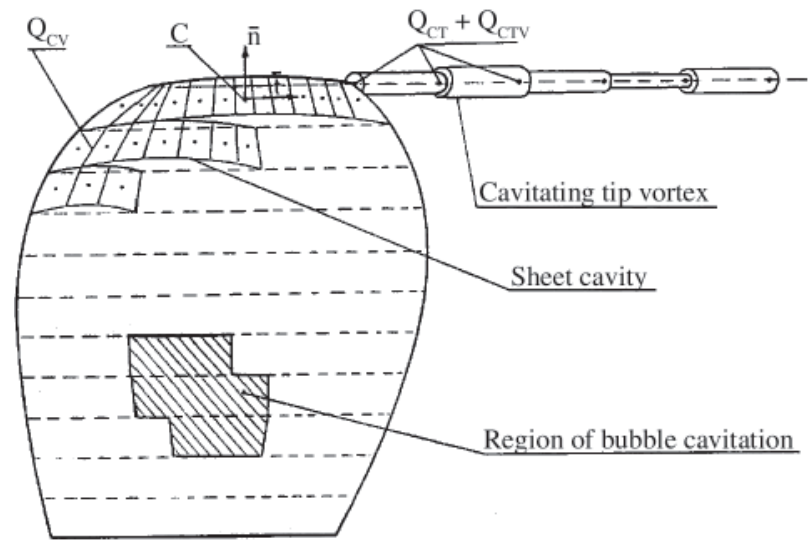

Fig. 5. Cavitating tip vortex model in the original analysis method. 
Such simple model does not account for many of the complicated vortex flow phenomena (cf. [3]), but still is able to reproduce the basic, physically realistic dependence of the generated pressure pulses on the basic mechanisms of the propeller - rudder interaction.

In the numerical model developed under the above assumptions each element of the cavitating tip vortex is treated as an independent section of an infinite circular cylinder, filled with gas/vapour mixture and acted upon by the external pressure field which is generated due to interaction of propeller and rudder. Propeller effect is calculated by using lifting surface theory, while rudder effect is calculated by using boundary element method. Example of the pressure field calculated by using this approach in the vicinity of the rudder leading edge at zero deflection is shown in Fig. 6. This figure shows the pressure distribution in the horizontal plane located above propeller shaft and passing through the point where vortex hits the rudder. The orange and red colours show the region of reduced pressure while the shades of green and blue show the regions of increased pressure. The asymmetry of the pressure distribution despite the nominal zero rudder deflection results from the propeller induced velocity, which generates a nonzero angle of attack.

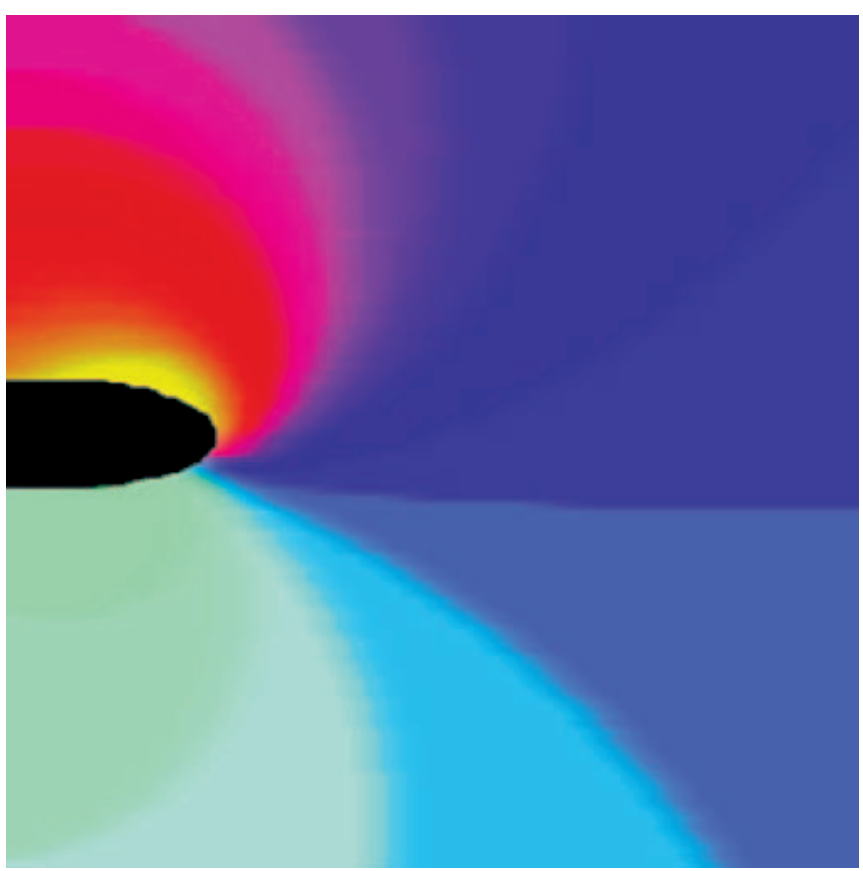

Fig. 6. Calculated pressure field around the rudder at zero deflection

In the Rankine vortex model all vorticity is concentrated inside a finite diameter core, which rotates as a rigid body, while the flow around the core is irrotational. This leads to the following formulae for the tangential induced velocity:

$$
\begin{gathered}
\mathrm{V}_{\mathrm{T}}=\frac{\Gamma}{2 \pi \mathrm{r}} \text { for } \mathrm{r} \geq \mathrm{R}_{\mathrm{C}} \\
\mathrm{V}_{\mathrm{T}}=\frac{\Gamma}{2 \pi \mathrm{R}_{\mathrm{C}}}\left(\frac{\mathrm{r}}{\mathrm{R}_{\mathrm{C}}}\right) \text { for } \mathrm{r} \leq \mathrm{R}_{\mathrm{C}}
\end{gathered}
$$

where:

$\Gamma \quad$ - the vortex circulation,

$r$ - the radial coordinate,

$\mathrm{R}_{\mathrm{C}}$ - the radius of the Rankine vortex core.

Vortex circulation in the above formula is taken from the unsteady lifting surface model of the propeller blade and is a function of propeller blade position. The vortex core radius is usually related to the boundary layer thickness in the tip region of the blade, in this case at the relative radius 0.95 . This leads to the following approximate relation:

$$
\mathrm{R}_{\mathrm{C}}=\frac{0.37 \mathrm{C}}{\mathrm{Re}^{0.2}}
$$

where:

Re - the Reynolds number,

C - the blade section chord length at relative radius 0.95 .

Then the pressure distribution around the Rankine vortex may be determined according to the following formulae:

$$
\begin{gathered}
\mathrm{p}=\mathrm{p}_{\infty}-\frac{\rho \Gamma^{2}}{8 \pi^{2} \mathrm{r}^{2}} \text { for } \mathrm{r} \geq \mathrm{R}_{\mathrm{C}} \\
\mathrm{p}=\mathrm{p}_{\infty}-\frac{\rho \Gamma^{2}}{8 \pi^{2} \mathrm{R}_{\mathrm{C}}^{2}}\left[\left(\frac{\mathrm{R}_{\mathrm{C}}}{\mathrm{r}}\right)^{2}-2\right] \text { for } \mathrm{r} \leq \mathrm{R}_{\mathrm{C}}
\end{gathered}
$$

where:

$p_{\infty}$ - the pressure far away from the vortex

$\rho$ - the water density

$\mathrm{r}$ - the radial coordinate.

The minimum pressure is attained in the vortex centre and its value may be determined as:

$$
\mathrm{p}_{\min }=\mathrm{p}_{\infty}-\frac{1}{4 \pi^{2}}\left(\frac{\Gamma}{\mathrm{R}_{\mathrm{C}}}\right)^{2}
$$

The inception of the tip vortex cavitation is determined by analyzing the behaviour of a cavitation nuclei in the pressure field generated by the tip vortex. It is assumed that nuclei present in water are sucked due to pressure force into the vortex centre and then their dynamics is studied using the standard Rayleigh - Plesset equation for a gas-filled spherical bubble:

$$
\frac{\mathrm{d}^{2} \mathrm{R}_{\mathrm{B}}}{\mathrm{dt}^{2}}\left[\frac{\Delta \mathrm{p}}{\rho}-\frac{3}{2}\left(\frac{\mathrm{dR}_{\mathrm{B}}}{\mathrm{dt}}\right)^{2}-\frac{2 \sigma}{\rho \mathrm{R}_{\mathrm{B}}}-\frac{4 \mu}{\rho \mathrm{R}_{\mathrm{B}}} \frac{\mathrm{dR}_{\mathrm{B}}}{\mathrm{dt}}\right] \frac{1}{\mathrm{R}_{\mathrm{B}}}
$$

where:

$\mathrm{R}_{\mathrm{B}}$ - the bubble radius

$\Delta \mathrm{p}$ - the pressure difference across the bubble wall

$\mathrm{t}$ - the time

$\sigma \quad$ - the water surface tension

$\mu \quad$ - the dynamic viscosity coefficient.

The above given equation is solved numerically by using Runge - Kutta method with a very short time step of 1 [ $\mu \mathrm{s}]$. The pressure difference governing the bubble growth is computed in each time step from formulae $(4,5,6)$. The initial conditions for this solution must include the initial bubble radius. In most calculations it is taken equal to 0.05 [mm], which corresponds to the typical size of cavitation nuclei present in the water. Inception of tip vortex cavitation is signalled when the bubble radius reaches the value of $0.25[\mathrm{~mm}]$. This value is in fact an empirical calibration parameter, determined on the basis of comparison of experimental and calculated inception conditions.

Once the inception of the tip vortex cavitation is diagnosed the initial radius of a cylindrical section of the cavitating kernel, just after leaving the blade, may be determined as:

$$
\mathrm{R}=\frac{\Gamma}{2 \pi} \sqrt{\frac{\rho}{2\left(\mathrm{p}_{\infty}-\mathrm{p}_{\mathrm{V}}\right)}}
$$

where: $p_{\mathrm{V}}$ is the critical vapour pressure. 
The dynamics of each section of the cavitating vortex kernel is calculated by using the Rayleigh-Plesset equation adapted to the cylindrical geometry. In this case the flow is treated as two-dimensional and purely vaporous content of the kernel is assumed, what leads to the following equation:

$$
\begin{gathered}
-\frac{\mathrm{d}^{2} \mathrm{R}}{\mathrm{dt}^{2}} \mathrm{R} \ln \mathrm{R}-\left(\frac{\mathrm{dR}}{\mathrm{dt}}\right)^{2}\left(\ln \mathrm{R}+\frac{1}{2}\right)+ \\
+\frac{\sigma}{\rho \mathrm{R}}+\frac{2 \mu \mathrm{dR} / \mathrm{dt}}{\rho \mathrm{R}}=\frac{\Delta \mathrm{p}(\mathrm{t})}{\rho}
\end{gathered}
$$

where:

$\mathrm{R}$ - the radius of the cylindrical section of the cavitating vortex kernel

$\mathrm{t}$ - the time

$\sigma$ - the surface tension of water

$\mu$ - the dynamic viscosity of water

$\rho$ - the density of water

$\Delta \mathrm{p}$ - the pressure difference across the vortex kernel wall.

This equation is solved numerically by using the Runge Kutta method. In the solution process two levels of time steps are used. The first level time step $\Delta \mathrm{T}$ is related to the propeller blade angular step in the non-uniform inflow and typically it is of order of $5-10$ milliseconds in full scale and $0.5-1.0$ milliseconds in model scale. The second level time step is used in numerical solution of the dynamics equation (1) and is typically taken as $\Delta \mathrm{t}=0.01 \Delta \mathrm{T}$, i.e. $50-100$ microseconds in full scale or 5-10 microseconds in model scale, although this may be varied if necessary. The external pressure acting on each vortex section is taken at the section centre and linearly approximated within each time step $\Delta \mathrm{T}$. The numerical solution of equation (1) is based on the initial conditions defining $\mathrm{R}$ and $\mathrm{dR} / \mathrm{dt}$ and it yields the values of $\mathrm{R}$ and $\mathrm{dR} / \mathrm{dt}$ at the end of each time step $\Delta \mathrm{T}$. These values replace the initial values for the same vortex section in the next time step. The entire procedure is illustrated in Fig. 7.

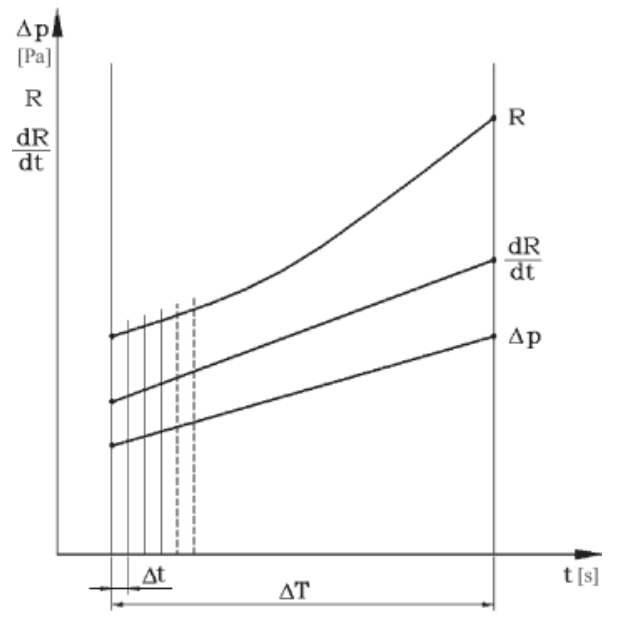

Fig. 7. Principle of numerical solution of equation (1) for a vortex section.

When the values of $\mathrm{R}$ and $\mathrm{dR} / \mathrm{dt}$ are determined for each $\Delta \mathrm{T}$ the effect of the cavitating tip vortex dynamics on the pulsating pressure field generated by the entire propeller - rudder system, may be calculated. This is done following the approach already incorporated in the propeller analysis method [8]. In this approach each cavitating tip vortex section is modelled by a point source, described by its mean value $\mathrm{Q}$, constant within each $\Delta \mathrm{T}$ and reflecting the quasi-steady displacement effect and by $\mathrm{dQ} / \mathrm{dt}$, reflecting the vortex dynamics. Both these values are employed in calculation of pressure pulses according to the linear form of the Cauchy-Lagrange equation:

$$
\mathrm{P}_{\mathrm{H}}=\frac{\rho}{4 \pi}\left(\mathrm{V}_{\mathrm{S}} \sum_{\mathrm{i}} \frac{\mathrm{Q}_{\mathrm{i}} \mathrm{x}_{\mathrm{i}}}{1_{\mathrm{i}}^{3}}+\sum_{\mathrm{i}} \frac{\mathrm{Q}_{\mathrm{i}}}{1_{\mathrm{i}}^{2}} \frac{\mathrm{dl}_{\mathrm{i}}}{\mathrm{dt}}-\sum_{\mathrm{i}} \frac{1}{1_{\mathrm{i}}} \frac{\mathrm{dQ}_{\mathrm{i}}}{\mathrm{dt}}\right)
$$

where:

$\mathrm{P}_{\mathrm{H}}$ - the pulsating pressure

$\mathrm{V}_{\mathrm{S}}$ - the ship velocity

$1^{\mathrm{S}}$ - the distance from source to the calculation point

$\mathrm{x}$ - the component of $\mathrm{r}$ in direction of ship velocity.

The sources in the above given equation are calculated in the following way:

$$
\begin{gathered}
\mathrm{Q}_{\mathrm{i}}=\pi\left(\mathrm{R}_{\mathrm{i}}^{2}-\mathrm{R}_{\mathrm{i}-1}^{2}\right) \sqrt{\mathrm{V}_{\mathrm{S}}^{2}+(\pi \mathrm{Dn})^{2}} \\
\frac{\mathrm{dQ}_{\mathrm{i}}}{\mathrm{dt}}=\pi\left[\left(\frac{\mathrm{dR}}{\mathrm{dt}}\right)^{2}-\left(\frac{\mathrm{dR}_{\mathrm{i}-1}}{\mathrm{dt}}\right)^{2}\right] \sqrt{\mathrm{V}_{\mathrm{S}}^{2}+(\pi \mathrm{Dn})^{2}}
\end{gathered}
$$

where:

D - the propeller diameter

$\mathrm{n}$ - the number of propeller revolutions per second

The equation for $\mathrm{P}_{\mathrm{H}}$ yields the values of the variable part of pressure at prescribed locations for each $\Delta \mathrm{T}$, i.e. for each analyzed angular propeller blade positions. These values are added to the contributions from propeller hydrodynamic loading and thickness, from rudder loading and thickness and from cavitation phenomena developed on the propeller and rudder. The total pressure pulses are resolved into harmonics.

\section{COMPARISON OF THE CALCULATED AND EXPERIMENTALLY MEASURED RESULTS}

The above described numerical method was used to calculate the pressure pulsations induced by the cavitating tip vortex interacting with the rudder. The calculation was performed for the full scale configuration corresponding to the model used in the experiments presented in the Introduction. The configuration is shown in Fig. 8, while the basic data of the propeller are presented in Tab. 2.

Tab. 2. Main data of the propeller.

\begin{tabular}{|c|c|c|c|c|}
\hline \multicolumn{3}{|c|}{ Propeller diameter } & \multicolumn{2}{c|}{$\mathbf{D = 8 . 2 0 0 [ \mathrm { m } ]}$} \\
\hline \multicolumn{3}{|c|}{ Number of blades } & \multicolumn{2}{c|}{$\mathbf{Z = 5}$} \\
\hline \multicolumn{2}{|c|}{ Number of revolutions } & \multicolumn{2}{c|}{ RPM $=\mathbf{9 9 . 0}[\mathbf{r p m}]$} \\
\hline r/R & $\mathbf{C}[\mathbf{m}]$ & $\mathbf{P} / \mathbf{D}[-]$ & $\mathbf{S}[\mathbf{m}]$ & $\mathbf{M}[\mathbf{m}]$ \\
\hline 0.25 & 2.2875 & 0.9694 & -0.096 & 0.0979 \\
\hline 0.4 & 2.5913 & 1.0167 & -0.316 & 0.0834 \\
\hline 0.5 & 2.7779 & 1.0402 & -0.387 & 0.0715 \\
\hline 0.6 & 2.9325 & 1.0539 & -0.337 & 0.0632 \\
\hline 0.7 & 3.0323 & 1.0547 & -0.153 & 0.0578 \\
\hline 0.8 & 3.0416 & 1.0352 & 0.152 & 0.0516 \\
\hline 0.9 & 2.8226 & 0.9859 & 0.569 & 0.0417 \\
\hline 0.95 & 2.3355 & 0.9494 & 0.834 & 0.0321 \\
\hline 1.0 & 0.0 & 0.9090 & 1.156 & 0.0 \\
\hline
\end{tabular}

where:

C - blade section chord lengths

$\mathrm{P} / \mathrm{D}$ - pitch coefficients

S - skewback ordinates

$\mathrm{M}$ - mean line camber

$\mathrm{r}$ - local radius

$\mathrm{R}$ - propeller radius. 


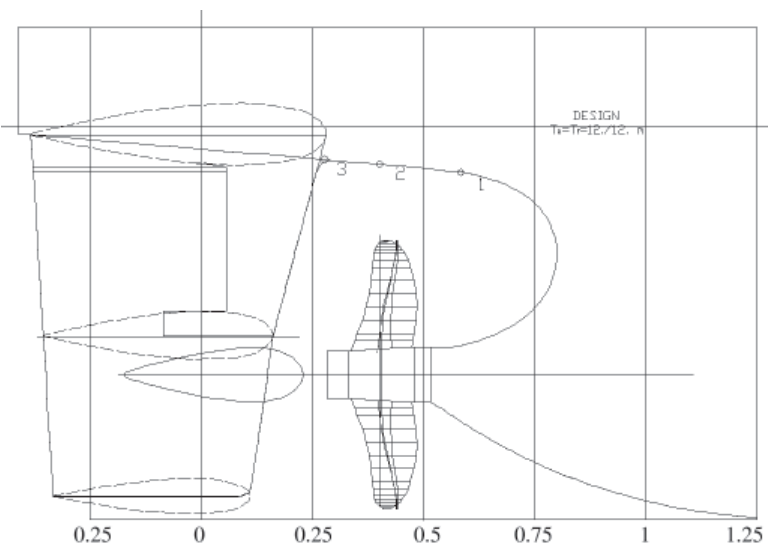

Fig. 8. Configuration of propeller and rudder used in calculations.

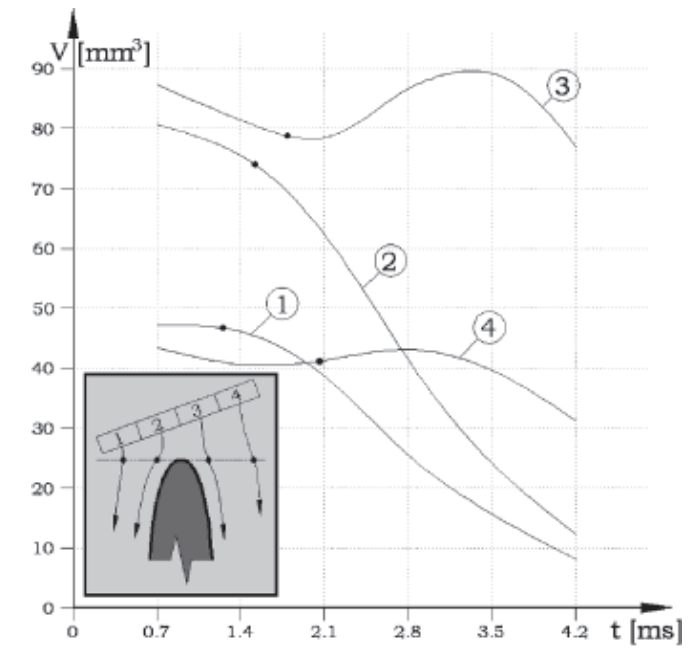

Fig. 9. Calculated time history of selected sections of the cavitating tip vortex.

Tab. 3. Calculation results by using the new model

\begin{tabular}{|c|c|c|c|}
\hline Pickup No. & $\begin{array}{c}\text { Measured } \\
\text { with rudder }\end{array}$ & $\begin{array}{c}\text { Calculated } \\
\text { without } \\
\text { rudder }\end{array}$ & $\begin{array}{c}\text { Calculated } \\
\text { with rudder }\end{array}$ \\
\hline 1 & 0.976 & 1.480 & 1.563 \\
\hline 2 & 2.630 & 1.880 & 2.470 \\
\hline 3 & 2.731 & 1.890 & 2.658 \\
\hline
\end{tabular}

\section{CONCLUSIONS}

The above presented model of interaction of the propeller cavitating tip vortex with the rudder incorporates the influence of the following important factors on the cavitating tip vortex dynamics:

- structure of the non-uniform velocity field at the inflow to the propeller,

- geometry and operating parameters of the propeller,

- geometry, location and deflection of the rudder.

Initial results of the calculations show that the new model is fully capable of predicting realistically the additional pressure pulses generated by the interaction of the cavitating propeller tip vortex with the pressure field around the rudder.

The model obviously does not account for important secondary phenomena such as the disintegration of the vortex in the rebound phase, described for example by Tunc and Delale [10]. As this disintegration process dissipates energy it may be expected that the simple model above presented has the tendency to overestimate the induced pressure pulsations. This means that the calculation results should be on the "safe side".

\section{Acknowledgement}

The author would like to acknowledge kind co-operation of the Ship Design and Research Centre (CTO SA) in Gdansk which supplied the experimental results employed in this paper.

\section{NOMENCLATURE}

C - propeller blade section chord length

D - propeller diameter

1 - distance from the source to the calculation point

M - propeller blade section mean line camber

$\mathrm{n}$ - number of propeller revolutions per second

$\mathrm{P} / \mathrm{D}$ - propeller blade section pitch coefficient

$\mathrm{P}_{\mathrm{H}}$ - pulsating pressure

p - local pressure

$\mathrm{p}_{\infty} \quad-$ pressure far away from the vortex

$\mathrm{p}_{\min }-$ minimum pressure at the vortex centre

$\mathrm{p}_{\mathrm{v}}$ - critical vapour pressure

$\Delta \mathrm{p}$ - pressure difference across the wall

$\mathrm{Q}-$ intensity of the source modeling the vortex kernel

$\mathrm{R}$ - radius of the cylindrical section of the cavitating vortex kernel

$R_{B}$ - radius of the spherical cavitation bubble

$R_{C}$ - radius of the Rankine vortex core

$\mathrm{Re}$ - Reynolds number

r - radial coordinate

$\mathrm{S}$ - propeller blade section skewback ordinate

$\Delta \mathrm{T}$ - time step between the consecutive blade positions

$\Delta \mathrm{t} \quad$ - time step in the Runge-Kutta method

t - time

$\mathrm{V}_{\mathrm{S}}-$ ship velocity

$\mathrm{V}_{\mathrm{T}}$ - tangential velocity induced by the Rankine vortex

$\mathrm{x}-$ component of 1 in the direction of the ship velocity

$\Gamma \quad$ vortex circulation

$\mu \quad-$ dynamic viscosity coefficient of water

- density of water

- surface tension of water

\section{BIBLIOGRAPHY}

1. Couty Ch., Farhat M., Avellon F.:Physical Investigation of a Cavitation Vortex Collapse. Proceedings of the $4^{\text {th }}$ Intern. Symp. on Cavitation CAV2001, Pasadena, USA, 2001

2. Krasilnikov V.I., Berg A., Oye I.J.: Numerical Prediction of Sheet Cavitation on Rudder and Podded Propeller Using Potential and Viscous Flow Solutions. Proceedings of the $5^{\text {th }}$ Intern. Symp. on Cavitation CAV2003, Osaka, Japan, 2003

3. Kuiper G.: New Developments Around Sheet and Tip Vortex Cavitation on Ship Propellers. Proceedings of the $4^{\text {th }}$ Intern. Symp. on Cavitation CAV2001, Pasadena, USA, 2001

4. Lee H.S., Kinnas S.A. et al.: Numerical Modelling of Propeller and Rudder Sheet Cavitation Including Propeller-Rudder Interaction and the Effects of the Tunnel. Proceedings of the 5th Intern. Symp. on Cavitation CAV2001, Pasadena, USA 2001

5. Lee S.K.: Numerical Study-Propeller/Rudder Cavitation of Fast Containership. Proceedings of the $3^{\text {rd }}$ Intern. Shipbuilding Conference, St. Petersburg, Russia, 2002

6. Shen Y.T, Remmers K.D. Jiang C.W.: Effects of Ship Hull and Propeller on Rudder Cavitation. Journal of Ship Research, Vol.41, No. 3, 1997

7. Szantyr J.A.: Analytical Prediction of Propeller Cavitation. The Naval Architect July/August 1991

8. Szantyr J.A.: A Method for Analysis of Cavitating Marine Propellers in Non-uniform Flow. Intern. Shipbuilding Progress Vol.41, No.427, 1994

9. Szantyr J.A.: A Computational Model of the Propeller Cavitating Tip Vortex Interacting With the Rudder. $6^{\text {th }}$ International Conference on Cavitation CAV'06, Wageningen, The Netherlands, 24-26 September 2006

10.Tunc M., Delale C.F.: Energy dissipation due to fission of cavitating bubbles. Proceedings of the $5^{\text {th }}$ Intern. Symp. on Cavitation CAV2003, Osaka, Japan, 2003 